\begin{tabular}{|l|l|}
\hline Marxismo y cuestión nacional & Titulo \\
\hline Kohan, Néstor - Autor/a; & Autor(es) \\
\hline $\begin{array}{l}\text { De Raíz Diversa. Revista Especializada en Estudios Latinoamericanos (Vol. 3 no. 5 } \\
\text { ene-jun 2016) }\end{array}$ & En: \\
\hline México D.F. & Lugar \\
\hline $\begin{array}{l}\text { Programa de Posgrado en Estudios Latinoamericanos,_Universidad Nacional } \\
\text { Autónoma de México }\end{array}$ & Editorial/Editor \\
\hline 2016 & Fecha \\
\hline $\begin{array}{l}\text { Guevara, Che; Nación; Revolución; Clases sociales; Cuestión nacional; Marxismo; } \\
\text { América Latina; }\end{array}$ & Colección \\
\hline Artículo & Temas \\
\hline "htp://biblioteca.clacso.edu.ar/Mexico/ppel-unam/20160630032145/5._Marxismo__ccuestion_nacional_Nestor_Kohan.pdf" & Tipo de documento \\
\hline $\begin{array}{l}\text { Reconocimiento-No Comercial-Sin Derivadas CC BY-NC-ND } \\
\text { http://creativecommons.org/licenses/by-nc-nd/2.0/deed.es }\end{array}$ & Licencia \\
\hline
\end{tabular}

Segui buscando en la Red de Bibliotecas Virtuales de CLACSO http://biblioteca.clacso.edu.ar

Consejo Latinoamericano de Ciencias Sociales (CLACSO)

Conselho Latino-americano de Ciências Sociais (CLACSO)

Latin American Council of Social Sciences (CLACSO)

www.clacso.edu.ar
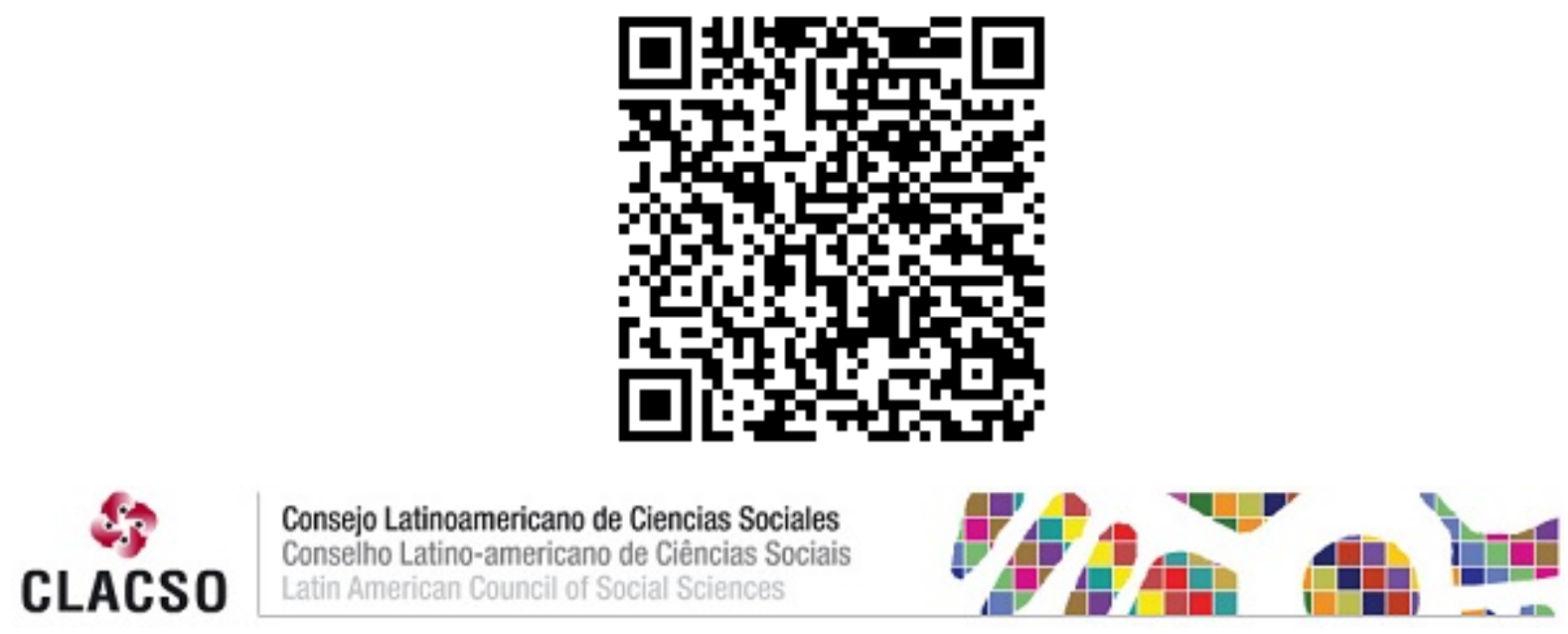


\title{
Marxismo y cuestión nacional
}

\author{
NÉSTOR KOHAN*
}

RESUMEN: El artículo explora la relación entre el marxismo y la cuestión nacional desde una óptica latinoamérica. Señala que puede apreciarse un viraje teórico dentro de la obra de Karl Marx, desde las investigaciones que realizó a partir de la década de los cincuenta del siglo xIx. Dicho cambio en la mirada que Marx tuvo de las naciones periféricas fue abandonado por aquellos que trataron de desarrollar su legado teórico. Empero, el artículo avanza en la comprensión de la originalidad de algunos marxistas latinoamericanos como Ernesto Che Guevara o José Carlos Mariateguí para recuperar el sentido anti-imperialista de las luchas latinoamericanas en las cuales una figura como la de Simón Bolívar se vuelve fundamental para entender el devenir de las luchas de liberación en esta región.

Palabras Clave: Marxismo, nación, clase, guevarismo, revolución.

Aвstract: The article explores the relationship between Marxism and the national question from a Latin American perspective. Notes that can be seen a theoretical shift in the work of Karl Marx, which from investigations carried out from the fifties of the nineteenth century. This change in the look that Marx had peripheral nations was abandoned by those who tried to develop their theoretical legacy. However, the article advances in the understanding of the originality of some Latin American Marxists like Ernesto Che Guevara or Jose Carlos Mariategui to recover the anti-imperialist struggles of the Latin American sense in which a figure like Simon Bolivar becomes essential to understand the future of the liberation struggles in this region.

KEYWORDS: Marxism, nation, class, Guevarism, revolution.

Recibido: 10 de junio de 2015. ACEPTado: 20 de octubre de 2015.

\section{MARX Y SU REFLEXIÓN SOBRE EL PROBLEMA NACIONAL}

\section{$\mathrm{L}$}

a posición histórica del marxismo sobre el problema nacional no ha sido unívoca ni uniforme. En sus primeros escritos Marx y Engels tenían, junto a su humanismo universalista y al internacionalismo, un punto de vista cosmopolita, sintetizado en la expresión "los trabajadores no tienen patria" del Manifiesto comunista (1848). Ese mismo año Engels escribía: "En América hemos presenciado la conquista de México la que nos ha

Profesor e investigador del CONICET en Argentina, <miseriadelafilosofia@gmail.com>. 
complacido. Constituye un progreso, también, que un país ocupado hasta el presente exclusivamente de sí mismo, desgarrado por perpetuas guerras civiles e impedido de todo desarrollo, un país que en el mejor de los casos estaba a punto de caer en el vasallaje industrial de Inglaterra, que un país semejante sea lanzado por la violencia al movimiento histórico. Es en interés de su propio desarrollo que México estará en el futuro bajo la tutela de los Estados Unidos" (1848). Apenas un año después Engels se pregunta: “ $¿ \mathrm{O}$ acaso es una desgracia que la magnífica California haya sido arrancada a los perezosos mexicanos, que no sabían qué hacer con ella?" (1849). En sus artículos sobre "La dominación británica en la India" (1853) Marx justifica la penetración del colonialismo inglés en el oriente en nombre del "progreso histórico" (aún cuando se queja en el terreno ético de los métodos salvajes de los británicos). En ese horizonte Engels hacía suya la concepción de Hegel sobre los "Pueblos sin historia", naciones periféricas condenadas, supuestamente, a no tener un estado propio. El triste y erróneo artículo de Marx sobre Simón Bolívar (enero de 1858) constituye probablemente la última prolongación de ese paradigma eurocéntrico, moderno, cosmopolita y progresista del Manifiesto comunista. A partir de allí Marx y Engels revisan su propia teoría, amplían notablemente su mirada del mundo (empiezan a hacerlo estudiando el comercio exterior de Inglaterra y sus colonias), comienzan a simpatizar con las rebeldías del mundo periférico, colonial y dependiente y reflexionan agudamente sobre el problema nacional desde un ángulo completamente distinto. Desde fines de la década de 1850 y sobre todo en las de 1860 y 1870 , abandonan el cosmopolitismo, conservando el internacionalismo, pero articulado ahora con una mayor comprensión del problema nacional. En su trayectoria teórica y científica se produce una fuerte discontinuidad y un viraje donde radicalizan su crítica del capital europeo occidental y su expansión "progresista" que aplasta los pueblos y somete las naciones de la periferia colonial o dependiente. Irrumpen entonces en su producción teórica India, China, Birmania, Rusia, Persia, islas Jónicas, América Latina, África e incluso en el interior de Europa las "atrasadas" Irlanda, Polonia y España.

\section{CONCLUSIÓN POLÍTICA DE UN VIRAJE TEÓRICO}

Estudiando en 1854 la revolución española Marx lee una frase programática y emblemática que lo deslumbra, pronunciada en 1810 por el indigena 
americano Dionisio Inca Yupanqui en las cortes de Cádiz: "Un pueblo que oprime a otro pueblo no puede ser libre" (Yupanqui se refiere a la opresión del pueblo español sobre los pueblos indígenas y mestizos de Nuestra América). Marx la hace suya y la aplicará en 1869 cuando se ocupe de Irlanda, reformulando la expresión de Yupanqui para el caso del proletariado inglés y el pueblo de su colonia Irlanda (Lenin utilizará reiteradamente la expresión que Marx adopta del indígena Yupanqui en sus escritos sobre la cuestión nacional, lo cual demuestra que los americanos hemos contribuido también a la gestación del marxismo, incluso del marxismo clásico europeo). El proletariado inglés - supuestamente depositario de "la misión civilizadora del progreso"- no liberará las colonias; son las colonias las que se liberarán a sí mismas, posibilitando la emancipación del proletariado metropolitano. Una inversión completa del eurocentrismo colonial y del cosmopolitismo "progresista".

Esa crítica ácida contra el eurocentrismo y el euroccidentalismo desarrollada en sus escritos sobre China de 1853 y en los Grundrisse [primeros borradores de 1857-58 de El Capital] se profundizará aún más en la carta de Marx de 1877 a la redacción del periódico ruso Anales de la patria y en los extensos borradores de su correspondencia de 1881 con Vera Zasulich, así como también en sus Apuntes etnológicos de 1880-1882. En todos esos materiales de madurez Marx ubica en el centro de sus reflexiones teóricas a la periferia del sistema mundial capitalista, al mundo colonial y dependiente, sometiendo a crítica la mirada cosmopolita, ingenuamente apologista del "progreso". Abandona terminantemente el cosmopolitismo y defiende con entusiasmo las causas nacionales de Irlanda, Polonia y otros países sometidos que luchan por su liberación nacional. Incluso en esa época, según revela su correspondencia, simpatiza abiertamente con los métodos de lucha armada de los irlandeses y los populistas rusos que realizan atentados contra el zar. En su corpus teórico de madurez el eje se desplazó del centro europeo a las periferias coloniales y dependientes. Marx no duda en apoyar la lucha armada de estos pueblos rebeldes.

¡Cuánto desconocimiento y cuanta ignorancia sobre Marx tienen los supuestos "eruditos" académicos del marxismo que utilizan frases sueltas y descontextualizadas de este genio del pensamiento para desconocer el papel del imperialismo contemporáneo, apoyando bochornosamente con jerga "de izquierda" y poses supuestamente "internacionalistas" los bombardeos neocoloniales del Pentágono y la OTAN en Libia, las guerras de 
saqueo en Afganistán e Irak, las intervenciones norteamericanas en Siria y Venezuela y muchas otras hazañas "humanitarias" del imperialismo! Desde ese ángulo, pretendidamente cosmopolita y eurocéntrico, han llegado a apoyar a Margaret Thatcher y su aventura neocolonial en nuestras islas Malvinas, donde la отAN construyó una base militar nuclear.

\section{DEBATES HISTÓRICOS EN EL MARXISMO POSTERIOR A MARX}

Después de Marx lamentablemente la Segunda Internacional desconoce el viraje teórico del maestro, retrocede y vuelve a incurrir en el peor eurocentrismo. Para la socialdemocracia el socialismo es cuestión de gente blanca, urbana y europea. Así pensaban H. van Kol, Emilio Vandervelde y muchos otros reformistas. En el congreso de la II Internacional de 1907, en Stuttgart, las posiciones que declaraban "no repudiar ni en principio ni para siempre toda forma de colonialismo, el cual, bajo un sistema socialista, podría cumplir una misión civilizadora" ganaron la adhesión de casi la mitad de la Internacional. Patético. Sólo Lenin y Rosa Luxemburg (aún discrepando entre sí sobre Polonia) se animaron a arremeter contra semejante engendro eurocéntrico. Lenin fue el más radical planteando como programa político estratégico la doctrina de la autodeterminación de las naciones, sin vasallaje imperial o colonial de ningún tipo, ni "humanitario", ni "civilizado", ni "socialista". De este modo Lenin abre el comunismo e incorpora en la revolución mundial a todas las culturas y naciones del Tercer Mundo. Ho Chi Minh recuerda en sus memorias cómo se puso a llorar de emoción cuando leyó a Lenin, pues hasta ese momento la Internacional era cosa de "blancos europeos y civilizados". Los amarillos, los negros, los indígenas, los mestizos y todo el mundo colonial, semicolonial y dependiente no entraban en "el colonialismo socialista" de la Segunda Internacional. Pero la apertura y el brillo de Lenin duraron poco. Tras su muerte, Stalin sacrifica el internacionalismo alcanzado subordinándolo a la razón de Estado y al interés estatal de Rusia con su doctrina del "socialismo en un solo país" que no sólo no resolvió el problema nacional sino que multiplicó una serie infinita de discordias y odios nacionales en los pueblos y culturas a los que se les negó la autodeterminación y se les impuso el idioma ruso por la fuerza.

En términos generales, en todos esos casos - desde el eurocentrismo occidentalista hasta la posición leninista de la autodeterminación de las 
naciones - la disyuntiva giraba en torno a naciones ya constituidas oprimidas por grandes potencias.

En Nuestra América Mariátegui aborda el problema desde un nuevo ángulo, ya que en nuestro continente las naciones no están plenamente constituidas. Las repúblicas heredadas de las primeras guerras de independencia (donde Bolívar y San Martín triunfan sobre el colonialismo europeo) son repúblicas bananeras hegemonizadas por las mezquinas y miopes clases dominantes criollas, patrias chicas y retazos fragmentados de la Patria Grande bolivariana. De la gran nación unificada a escala continental con la que soñaba Bolívar pasamos - gracias a la mano pérfida de Inglaterra y Estados Unidos- a más de 20 republiquetas, enemistadas entre sí (a tal punto que en Centro América hubo guerras hasta por el fútbol), que además oprimen a los pueblos originarios con una institucionalidad burguesa y oligárquica. Por eso Mariátegui reformula "la cuestión nacional" de los clásicos del marxismo europeo desde un ángulo muy novedoso. A partir de la revolución cubana y el auge de la insurgencia continental de los ' 60 y '70, comienzan a reivindicarse las primeras guerras de independencia de la Patria Grande como parte constitutiva del proyecto socialista y comunista contemporáneo.

LIBERACIÓN NACIONAL, REIVINDICACIONES IDENTITARIAS, ANTICAPITALISMO Y SOCIALISMO

La fórmula clásica según la cual la revolución socialista es "internacional por el contenido, nacional por la forma" me resulta hoy un poco esquemática. No creo que la identidad nacional latinoamericana sea simplemente un problema de "forma", una presentación "folclórica", externa y decorativa de algo que ya está completamente masticado y acabado. No existe un modelo universal (extraído de Europa occidental) que "se aplica" mecánicamente país por país, según las variaciones idiosincráticas del folclore local. La historia nacional está presente también en el contenido de las revoluciones de liberación nacional y social. Ejemplo: para la revolución cubana la herencia de Martí no es un adorno decorativo externo sino parte de su misma conformación y gestación histórica.

Por otro lado, no pondría en el mismo plano las luchas de liberación nacional a escala continental - sobre todo en perspectiva bolivariana, a escala de la Patria Grande- y los conflictos de dominación clasista - la 
lucha de clases - junto con los problemas de reivindicaciones identitarias, como la cuestión de género y las múltiples opciones de diversidad sexual, la cuestión del racismo u otras análogas. Todas esas perspectivas de análisis son legítimas y validas ya que abordan distintos tipos de opresión bajo el capitalismo pero se desarrollan y despliegan en planos diferentes de la lucha, no siempre equivalentes ni simétricos. ¿Dónde estaría la diferencia específica entre estas problemáticas? En su capacidad de aglutinar, convocar y articular rebeldías diversas contra el sistema capitalista. La Academia norteamericana y la francesa han elaborado y difundido una cantidad abrumadora de literatura teórica y política destinada a convencer al movimiento popular de que el mejor de los mundos posibles gira en torno a las luchas de gueto, a las reformas institucionales puntuales, a los juegos de lenguajes recíprocamente ajenos, intraducibles e inconmensurables de cada movimiento social. Esas academias y el pensamiento posmoderno han insistido durante 30 años que cualquier articulación totalizante que reúna las múltiples rebeldías en un frente común contra el capitalismo y el imperialismo es... "opresiva", "sustitucionista" y en última instancia "totalitaria". Curiosamente para ser libertario y políticamente "radical"... hay que conformarse con reformas institucionales que den cuenta de identidades particulares (por ejemplo, leyes antirracistas que protejan al pueblo judío de la marginación, ley del matrimonio igualitario para el movimiento gay, programas de discriminación positiva para los negros y negras afrodescendientes, etc.). Reformas institucionales en defensa de "la diversidad" plenamente compatibles con el sistema capitalista. No casualmente en EEUU, la potencia imperialista más opresiva, vigilante y represora del mundo (como reconocen el más teórico Noam Chomsky o el más práctico Snowden), hay generales gays, un presidente negro, ministros de origen judío y torturadoras mujeres. Un gran respeto por "la diversidad"... siempre dentro del capitalismo y el imperialismo, por supuesto.

A contramano de posmodernos y multiculturalistas, el gran desafío del marxismo revolucionario latinoamericano consiste en poder articular todas las rebeldías multicolores en un proyecto colectivo de hegemonía socialista apuntando a construir a escala de la Patria Grande ese sueño inacabado e inconcluso de Simón Bolívar cuando dijo "Para nosotros la patria es América”, así como para Martí "Patria es humanidad”. El socialismo y el comunismo internacionalistas no son grises, tienen múltiples colores. El rojo, si quiere triunfar sobre el capitalismo y el imperialismo, tiene que 
ser la síntesis integradora y aglutinadora de ese arco iris multicolor donde no pueden estar ausentes la identidad cultural de nuestros pueblos y la emancipación nacional de la Patria Grande, proyecto todavía inconcluso de nuestros primeros libertadores y libertadoras.

\section{LA CUESTIÓN NACIONAL Y EL GUEVARISMO EN ARGENTINA}

El Che Guevara no es una estrella solitaria, sino uno de los máximos exponentes de la revolución cubana y latinoamericana. Esa revolución se inspira, ya desde el asalto al cuartel Moncada de 1953, en el programa de José Martí. Más tarde, habiendo triunfado sobre el enemigo imperialista y la burguesía lumpen, mafiosa y prostituída de la isla, la revolución cubana sintetiza su mirada del problema nacional en la Segunda Declaración de La Habana, combinando tareas nacionales-antimperialistas con las específicamente socialistas. Hijo de ese horizonte, el Che comunista e internacionalista, recupera al mismo tiempo a San Martín (discurso del 25 de mayo de 1962 en La Habana), a Bolívar (en sus Cuadernos de lectura de Bolivia) y a Martí (en "Notas para el estudio de la ideología de la revolución cubana"). Según Pombo, sobreviviente de la guerrilla de Bolivia, el Che compartía con sus compañeros las lecturas sobre Juana Azurduy y la guerra de guerrillas de las republiquetas del Alto Perú contra el colonialismo español.

Aprendiendo del Che, diversos exponentes del guevarismo latinoamericano se esforzaron por sintetizar el método, la concepción del mundo y de la vida y la ideología marxista con las tradiciones nacionales indo-latino-nuestroamericanas. Desde Carlos Fonseca a Miguel Enríquez, desde Raúl Sendic a Roque Dalton, desde Camilo Torres a Manuel Marulanda Velez, incluyendo en esa familia continental al argentino Mario Roberto Santucho.

No casualmente el PRT [Partido Revolucionario de los Trabajadores] elige la bandera latinoamericana (no sólo argentina) del ejército de los Andes de San Martín para identificar sus emblemas en la fundación del ERP [Ejército Revolucionario del Pueblo].

Plantear que "no hay nada que reivindicar de la lucha independentista del siglo xix porque allí no había obreros" me parece expresión de una aguda ignorancia e incomprensión del marxismo y de su metodología histórica. Ese internacionalismo abstracto, pretendidamente cosmopolita e ignorante de nuestra historia en nombre del "clasismo", está más cerca del 
tímido reformista Juan B. Justo (que nunca entendió ni al colonialismo ni al imperialismo) que del Che Guevara, Lenin y sobre todo del propio Marx.

\section{DISPUTA IDEOLÓGICA POR EL SENTIDO DE LOS SÍMBOLOS NACIONALES}

Julio Antonio Mella solía repetir que la palabra "patria" en manos de la burguesía es como un tambor, suena muy fuerte pero está vacía. En cambio cuando son los sectores populares los que apelan a la tradición patriótica y nacional, el concepto de "patria" adquiere un sentido completamente distinto. Fundamentalmente en países como los nuestros, donde la dependencia jamás desapareció (incluso se profundizó), aunque la palabra "dependencia" haya circulado menos en la academia de los últimos 30 años. Que se utilice menos la palabra no significa que haya desaparecido la realidad que ese término designa. Lejos estamos del giro lingüístico donde todo queda prisionero del lenguaje y se evapora la realidad social. Más allá de los discursos y las palabras hay un mundo. En ese mundo social existe lucha de clases. En el ámbito de la cultura y la reproducción cotidiana del orden social, nada queda al margen de esa lucha de clases. Incluyendo la historia nacional y sus símbolos patrios. El San Martín de Videla (supuestamente un general blanquito y europeo, enemigo de Bolívar) y el de Robi Santucho o Rodolfo Walsh (concebido como un patriota latinoamericano, defensor de la Patria Grande, amigo y compañero de Bolívar) no sólo son distintos sino opuestos y antagónicos. El mismo año (1970) en que el genocida y torturador ejército argentino financiaba y producía la película $E l$ Santo de la Espada sobre San Martín, el ERP adoptaba su bandera como símbolo revolucionario. Quien controle el pasado, manejará el presente escribía George Orwell. Emancipar el pasado para liberar el futuro es la tarea del momento. La disputa del año 2010 por el Bicentenario de la independencia lo ha demostrado de manera muy clara.

\section{LIMITACIONES DE LA HISTORIA OFICIAL SOBRE LAS REVOLUCIONES DE INDEPENDENCIA EN AMÉRICA LATINA}

Entre los obstáculos destaquemos, en primer lugar, el eurocentrismo, que sigue gozando de prestigio hoy en día, bajo diversos ropajes. "Nuestra América se liberó... gracias a la invasión napoleónica de España. Napoleón es un derivado de la revolución francesa. Por lo tanto, sin revolución francesa, no existiría la independencia de Nuestra América”. Un relato sesgado, 
unilateral, deformado, que desconoce 500 años de resistencia continental y el ciclo que inician Tupac Amaru en 1780 y Haití una década después y que sólo concluye en 1824 con la batalla de Ayacucho. El historiador francés Pierre Chaunu - repetido en las academias hasta el cansancio- lo sintetizó diciendo que los latinoamericanos no nos independizamos, recibimos (como un regalo) la independencia. Falso, miserable, altanero y petulante.

En segundo lugar, la construcción de mitos, falsas dicotomías y panteones de la escuela del general Bartolomé Mitre, continuados por Sarmiento y Levene, a quienes se agregaron la Academia Argentina de la Historia (núcleo del gorilaje académico) y el Instituto Nacional Sanmartiniano (fundado por el ultracatólico José Pacífico Otero en el Círculo Militar). Esta corriente opone San Martín contra Bolívar, pretende desconocer el Plan revolucionario de operaciones de Mariano Moreno y condensa un elitismo insoportable. Eso en cuanto a la historia oficial, de factura liberal-conservadora y brutalmente eurocéntrica.

Por oposición a ella, el revisionismo rosista y católico, invirtió la ecuación liberal dejando intactos los términos. San Martín se convierte en un represor, la mazorca rosista en un modelo a imitar y así de seguido.

La historiografía mitrista liberal fue luego reemplazada en la historia oficial y en la Academia por el relato posmoderno según el cual rastrear las raíces de las luchas independentistas es incurrir en un supuesto "mito del origen", una impugnación que apunta a deslegitimar todo lo que contribuya a fortalecer la memoria histórica y la autoestima popular, dimensiones fundamentales de cualquier resistencia y proyecto revolucionario. Para el posmodernismo todo es "mito" menos... el mercado, la republica parlamentaria y el capitalismo.

Finalmente me encontré con la producción historiográfica de gente bien intencionada, con voluntad de fidelidad a Marx (en general al Marx cosmopolita previo a su viraje sobre el problema colonial y nacional), pero que seguía presa de modelos eurocéntricos y tipos ideales extraídos de la revolución industrial inglesa y la revolución política francesa. Una metodología que les impedía, a pesar de sus buenas intenciones, ajustar cuentas y hacer un beneficio de inventario con la historia apologética y oficial de la burguesía argentina. Para esta corriente, Sarmiento es un ídolo (tanto en el caso de la historiografía del stalinismo como en la del trotskismo), Bolívar un populista bonapartista y la clave de nuestra historia está en.... "el desarrollo de las fuerzas productivas". Por lo tanto, la mayor parte de 
las resistencias frente al colonialismo europeo terminan condenadas "porque no tenían un programa para desarrollar las fuerzas productivas”. En nombre de Marx, se termina coincidiendo con el aplauso apologético a los vencedores y la condena a los que resistieron. En algunos casos extremos se termina insultando a Bolívar para aplaudir a Bernardino Rivadavia (su gran enemigo argentino, paralelo a su enemigo colombiano Santander) o incluso se festeja la feroz y mugrienta guerra al Paraguay porque supuestamente.... "desarrolló las fuerzas productivas".

Frente a tantos equívocos historiográficos defendemos la pertinencia de una nueva mirada de nuestra historia, desde abajo y desde un ángulo marxista latinoamericano y descolonizador. Una nueva mirada de nuestras guerras de independencia y de nuestra lucha de clases, que reivindique con orgullo y con honor a nuestros miles y miles de masacradas y asesinados mientras resistían y luchaban heroicamente contra el colonialismo, hayan tenido o no un programa completo y explicitado hasta el más mínimo detalle para desarrollar las fuerzas productivas.

\section{EL AMOR DE LOS PUEBLOS, EL ODIO DEL IMPERIO}

Tanto en la historiografía académica (que circula entre los “especialistas") como en la literatura de divulgación (destinada para el gran público), en los artículos de periódicos como en la ensayística de ciencias sociales, Bolívar tiene mala prensa. "Dictador", "déspota", "Bonaparte tropical", "violento" y sobre todo... "populista". Así se lo ha (des)calificado. Es la mirada sórdida y absolutamente interesada del imperio, siempre disfrazada de "cientificidad", "objetividad" y equidistancia neutralmente valorativa. Desde William Tudor, belicoso y prepotente embajador norteamericano en el Perú en tiempos de la independencia, hasta los documentos del Pentágono de las últimas décadas, desde las viejas monarquías españolas o británicas del siglo xix hasta las monarquías europeas que -increíblemente - todavía en el siglo xxi se animan a gritarle a los representantes del Tercer Mundo “ ¿por qué no te callas?”, Bolívar no deja de generar odio y desprecio por parte de los amos del mundo. A esos imperios de ayer y de hoy probablemente no les interese una persona particular (pues a ese individuo lo tienen congelado en un par de inofensivas estatuas). Los irrita y les genera incomodidad el proyecto histórico, social, cultural y político que en él se inspira. Simón Bolívar, como el Che Guevara, se volvió todavía mucho más peligroso después de muerto. Bolívar y el Che, símbolos de 
rebeldías colectivas, se convirtieron en fuego incandescente, en emblemas de amor y sueños afiebrados que no logran terminar de apagarse, a pesar de los golpes de estado, la generalización del Mercado, las represiones y los miles y miles de desaparecidos que han regado nuestro continente del rojo color de la sangre. La insubordinación tenaz de los de abajo (tanto en el Tercer Mundo como en los pueblos que habitan las metrópolis imperiales), la falta de respeto por el orden establecido, el viejo sueño de construir la unidad de la Patria Grande y de terminar con todas las formas de dominación social, clasista y nacional, han convertido a Simón Bolívar en un fantasma insepulto que mantiene la pupila insomne de los poderosos y el corazón jadeante de la militancia revolucionaria y los pueblos en lucha. Mientras los voceros del poder no se cansan de insultarlo, tratando por todos los medios de resaltar el más mínimo detalle de su biografía que lastime su prestigio y su capacidad de generar admiración en los jóvenes rebeldes del siglo XXI, los pueblos que combaten por un mundo mejor (en todos los continentes) siguen encontrando en su ejemplo de vida el incentivo para alimentar las luchas actuales. El odio de los de arriba, el amor de los de abajo. Eso es Simón Bolívar. Así de sencillo y así de complejo al mismo tiempo.

\section{El SUEÑo de SIMÓN BolíVAR, QUIJOTE DE LA PATRIA GRANDE}

Nuestra época se ha tornado brutalmente "pragmática" y cortoplacista. Cuesta muchísimo planificar la vida cotidiana - el trabajo, el estudio, la pareja, la vivienda, los proyectos, etc.-, en términos de años o de décadas. Se vive al día, minuto a minuto, en la inestabilidad del instante fugaz, en el reinado de lo efímero y en la zozobra permanente, acorde a la crisis civilizatoria y los vaivenes del sistema capitalista. Se valoriza lo aparentemente eficaz, lo útil, lo que "sirve" para el día a día. En nuestro tiempo intentar pensar a largo plazo, lograr independizarse mínimamente de la inmediatez, tener una ética y una perspectiva de vida que desafíe a los poderosos, suele descartarse rápidamente como "una locura" y "un delirio". Por cada poro de nuestra existencia respira el Mercado. A eso se le llama sobrevivir. Todo comenzó, aparentemente, a inicios de 1960 cuando en la cultura oficial de las grandes metrópolis capitalistas, en sus ámbitos universitarios y en las publicaciones editoriales, se empezó a decretar el aparente "agotamiento de la política". A ello le sucedió el supuesto "ocaso 
de las ideologías", la pretendida "muerte del sujeto" y el ansiado "fin de los grandes relatos o narrativas". Incluso se llegó a postular nada menos que "el fin de la historia". De todo ello se dedujo, con total liviandad, que los sueños y las utopías “ya no estaban de moda”. Era la dictadura cínica e indiscutida del posmodernismo. Tenía pretensiones de eternidad, aunque duró tan solo unos 30 años. Pues bien, a contramano del espíritu y la sensibilidad posmoderna (ya por suerte deshilachados), si el Libertador tuvo alguna característica fue, precisamente, su capacidad de soñar, de imaginar un futuro a largo plazo completamente distinto al de su realidad inmediata. Simón Bolívar fue un gran soñador, de esos que sueñan despiertos y trabajan escrupulosamente en la realización de sus "fantasías" y "utopías" (como reclamaba Lenin a los soñadores). Por eso Bolívar le tuvo tanta admiración a don Quijote, aquel entrañable caballero andante que desde su ensueño solía arremeter contra los molinos de viento de una realidad mediocre y cruel que se le imponía y que él no se resignaba a aceptar. Al final de su vida el Libertador habría exclamado, frente a una biblioteca donde se encontraba Don Quijote de la Mancha, la inmortal obra de Cervantes: “¡Jesucristo, don Quijote y yo, hemos sido los más grandes majaderos de éste mundo!”. Sin duda, ese espíritu quijotesco constituye el núcleo central del pensamiento de Bolívar y el impulso más íntimo del bolivarianismo contemporáneo. Indomesticable, siempre vital y dispuesto a la lucha solidaria por un mundo mejor. Frente al reino mediocre del Mercado y el dinero, frente a la miseria espiritual del posmodernismo y las injusticias del sistema capitalista, la estrella de fuego de Simón Bolívar sigue ardiendo. Siglo y medio antes que el mayo francés, el sueño de Bolívar nos marcó el camino, cuando le respondió al general Páez: “¡Lo imposible es lo que nosotros tenemos que hacer, porque de lo posible se encargan los demás todos los días!”.

\section{LA ESTRELLA DE SIMÓN BOLÍVAR HOY}

De Bolívar reivindicamos su proyecto de liberación continental (independencia de España pero también integración regional y unidad continental), la conjugación de la lucha nacional y social (liberación de la esclavitud 50 años antes que EEUU y emancipación de la servidumbre de los pueblos originarios), su antimperialismo (identifica estratégicamente a EEUU como enemigo histórico de Nuestra América) y su doctrina polí- 
tico militar revolucionaria del pueblo en armas, condición de su triunfo sobre el colonialismo europeo luego de varias derrotas.

Bolívar constituye hoy un símbolo de rebeldía continental, como el Che Guevara quien, dicho sea de paso, era un convencido bolivariano (en su mochila guerrillera de Bolivia Guevara tenía reproducido el poema de Neruda en homenaje a Bolívar donde éste declara "despierto cada 100 años cuando despierta el pueblo"). Su visionario proyecto de Patria Grande, todavía inconcluso y pendiente, se ha tornado más actual que nunca en tiempos de globalización. La Patria Grande soñada por Bolívar (compartida por Miranda, San Martín, Mariano Moreno, Artigas y tantos otros y otras) nace en sus escritos en la Carta de Jamaica de 1815 y en el Congreso de Panamá de 1826 enfrentando la doctrina Monroe de 1823 cuyo lema "América para los americanos" condensa el proyecto geoestratégico del imperialismo norteamericano. No es casual que los documentos de Santa Fe IV, elaborados por los estrategas político-militares del Pentágono, identifiquen a Simón Bolívar (junto con la teología de la liberación y Antonio Gramsci) como uno de los principales enemigos actuales de Estados Unidos.

\section{CLASE Y NACIÓN}

En nuestra América, liberarnos entonces de la dominación colonial, neocolonial e imperialista presupone al mismo tiempo construir la Patria Grande. No habrá liberación nacional sin emancipación social y jamás lograremos reorganizar la nueva sociedad sobre bases no capitalistas ni mercantiles si al mismo tiempo no logramos constituir ese proyecto inacabado de Patria Grande, rompiendo con toda sumisión y dependencia. No hay ni puede haber dos "etapas" separadas (como le gustaba repetir al señor Stalin) ni dos revoluciones diferentes: el proceso de la revolución latinoamericana es y deberá ser al mismo tiempo socialista de liberación nacional, es decir, de liberación continental. La dominación de clase y la cuestión nacional no conforman procesos escindidos en tiempo y espacio sino hilos de un mismo tejido social que se conformó de esa forma - subordinada al sistema capitalista mundial a través de sus socios locales, las burguesías lúmpenes y dependientes- desde nuestros inicios históricos. Por eso Mariátegui - el primer marxista de Nuestra América- pudo escribir un siglo después de Bolívar que "La misma palabra Revolución, en 
esta América de las pequeñas revoluciones, se presta bastante al equívoco. Tenemos que reivindicarla rigurosa e intransigentemente. Tenemos que restituirle su sentido estricto y cabal. La revolución latinoamericana, será nada más y nada menos que una etapa, una fase de la revolución mundial. Será simple y puramente, la revolución socialista. A esta palabra, agregad, según los casos, todos los adjetivos que queráis: «antiimperialista», «agrarista», «nacionalista-revolucionaria». El socialismo los supone, los antecede, los abarca a todos". Ese es precisamente el programa bolivariano y mariateguista que retoma y actualiza Ernesto Che Guevara en el último de sus mensajes a los pueblos del mundo, oportunidad en la que partiendo de su experiencia concreta al frente de la Revolución cubana sintetiza su interpretación sociológica e historiográfica de la historia de Nuestra América, de donde deduce un proyecto estratégico y político a futuro: "Por otra parte las burguesías autóctonas han perdido toda su capacidad de oposición al imperialismo - si alguna vez la tuvieron- y sólo forman su furgón de cola. No hay más cambios que hacer; o revolución socialista o caricatura de revolución.

Hoy, en el siglo xxi, ya está completamente fuera de discusión que ese proyecto mariateguiano y guevarista de revolución socialista continental o, en otras palabras, ese proyecto de Patria Grande antiimperialista y socialista al mismo tiempo, está inspirado directamente en el ideario independentista bolivariano.

\section{EL MARXISMO BOLIVARIANO DEL SIGLO XXI}

Varias décadas después del asesinato del Che Guevara a manos de la CiA y el ejército boliviano (porque el Che, conviene recordarlo frente a tanto hipócrita que hoy lo homenajea como si fuera Gandhi o la Madre Teresa de Calcuta, no se murió en su cama de muerte natural ni de un resfrío...) el mensaje insumiso retorna. El posmodernismo ya tuvo sus dos minutos de fama y sus treinta segundos de gloria. Que en paz descanse, rodeado de tumbas académicas, becas millonarias y las pompas fúnebres de grandes monopolios de (in)comunicación. Sus ventrílocuos locales continúan moviendo las manos y la boca, siguen buscando oídos jóvenes para inculcar resignación y "realismo", pero ahora casi nadie los escucha. En Nuestra América vuelven a sonar los tambores de la rebelión. Cada vez se escuchan más cerca. Día a día son menos los que creen que el futuro está debajo de la bandera prepotente de los Estados Unidos de Nortea- 
mérica. Bolívar vuelve a inspirar nuevas rebeldías, las antiguas y otras nuevas que resignifican sus antiguas proclamas de liberación continental incorporando nuevas demandas, derechos y exigencias populares. Su inspiración contemporánea, a la altura del siglo xxi, asume las formas más variadas y los estilos más diversos, atravesando desde los movimientos sociales hasta los sacerdotes tercermundistas, desde los gobiernos bolivarianos hasta la lucha insurgente y guerrillera, desde el presidente Hugo Chávez hasta el Movimiento Continental Bolivariano (мСв) y las Fuerzas Armadas Revolucionarias de Colombia Ejército del Pueblo (FARC-EP). No es casual. Todos se inspiran en Simón Bolívar... ¿Este resurgir de la prédica bolivariana constituye una expresión de "folclore y carnaval latino" y una exótica cortina de humo tropical o expresa la crisis profunda de una manera posmoderna de entender la historia donde únicamente se destacaban las discontinuidades, los cortes absolutos y "el caprichoso, contingente y aleatorio suceder de capas geológicas" (como le gustaba decir a Michel Foucault)? ¿El hecho político y teórico de nuevas luchas sociales actuales que marcan una continuidad explícita y directa con las luchas históricas del pasado no merecería una reflexión de largo aliento y un nuevo programa de investigación dejando atrás los equívocos posestructuralistas de los años '80 y '90? En el horizonte del siglo Xxi vuelve a aparecer el antiguo pero nuevo proyecto integrador de todas las formas de lucha convergiendo en el sueño rebelde de la Patria Grande, una sola gran nación latinoamericana, una revolución socialista a escala continental y mundial. Un proyecto radical cuya nueva racionalidad histórica aspira a sembrar la diversidad multicolor de voces, luchas y rebeldías dentro de un suelo común de hegemonía socialista, antiimperialista y anticapitalista. No es cierto que "desapareció el sujeto”. ¡No! El sujeto vuelve y retorna multiplicado con mucha más fuerza (y menos ingenuidad) que antes. Dejando atrás el cinismo del doble discurso, el macartismo, la razón de Estado, la demonización y el delgado límite de las protestas "permitidas" (siempre restringidas a tímidas reformas de guetto, fagocitables dentro de las instituciones del sistema); el ejemplo insumiso de Bolívar nos invita a recuperar la vocación de poder — trágicamente «olvidada» o denostada por los nuevos reformismos-, la ética inflexible y la rebeldía indomesticable de los viejos comuneros, los bolcheviques, los combatientes libertarios y comunistas, los partisanos, los maquis, los guerrilleros insurgentes y todos los luchadores y luchadoras del Tercer Mundo. 
Si hoy Karl Marx anduviera por nuestros barrios, ¿no caminaría al lado nuestro repitiendo con José Martí "Patria es humanidad" y llevando en el hombro, también él, su bandera de Bolívar?

\section{BIBLIOGRAFÍA}

BOLÍVAR, S. (1981-1982); Obras Completas (tres vols.). Caracas: Librería Piñango.

CHAUNU, P. (1973); “Interpretación de la Independencia de América Latina”, en P. Chaunu, E. Hobsbawm y P. Vilar, La Independencia de América Latina. Buenos Aires: Nueva Visión.

GUEVARA, E. (1970); Obras (dos tomos). La Habana: Casa de las Américas.

HO CHI MINH (1968); Cuadernos de la cárcel. Buenos Aires: La rosa blindada.

KOHAN, N. (2010); Nuestro Marx. Caracas: Misión Conciencia.

, (2011); Simón Bolívar y la manzana prohibida de la revolución latinoamericana. Caracas: Trinchera.

, (2013); Simón Bolívar y nuestra independencia. Una lectura latinoamericana. Buenos Aires: Ediciones Amauta Insurgente.

LENIN, V. I. (1958-1960), Obras Completas, t. V. Buenos Aires: Cartago.

MARX, K. (1988), Los apuntes etnológicos de Karl Marx, transcritos, anotados e introducción por Lawrence Krader. Madrid: Siglo XXI. 